\title{
HÌNH THÁI ỐNG TỦY RĂNG HÀM LỚN THỨ NHẤT HÀM DƯỚI CỦA NGƯỜII HÀ NộI
}

\author{
Đinh Diệu Hồng*, Phạm Như Hải*, Đỗ Thị Thu Hương*, \\ Đào Thị Dung*, Nguyễn Anh Chi*
}

\section{TÓM TẮT}

Chụp cắt lớp vi tính chùm tia hình nón $(\mathrm{CBCT})$ là một cồng cụ có giá trị cho điều trị nội nha. Muc đích của nghiên cứu này là xác định hình thái của ổng tủy răng hàm lớn thứ nhất hàm dưới (răng số 6 hàm dưới). CBCT của 315 bệnh nhân đã được sử dụng. Kết quả như sau: $88,7 \%$ rắng 6 hàm dưới có 2 chẩn răng, $11,3 \%$ răng số 6 hàm dưới có 3 chân răng. 55,6\% răng số 6 hàm dưới có 2 ống tuỷ riêng biệt ở chân gần (Vertucci IV). 77,1\% răng số 6 hàm dưới chỉ có 1 ống tuỷ duy nhất (Vertucci I). Sự khác biệt về số lượng chân răng cũng như hình thái ống tuỷ bên phải và bên trái không có ý nghĩa thống kê. Sự khác biệt về số lượng chân răng cũng như hình thái ống tuỷ ở nam và nữ không có ý nghĩa thống kê.

Tư khóa: ống tủy, nội nha, cone-beam, răng hàm lớn thứ nhất hàm dưới.

\section{SUMMARY \\ ROOT CANAL MORPHOLOGY AND CONFIGURATION MANDIBULAR FIRST MOLARS OF HANOI SUBPOPULATION}

Cone-beam computed tomography (CBCT) is a valuable tool for endodontic treatment. The purpose of this study was to determine the morphology of the mandibular first molar canal. CBCT of 315 patients was used. The results are as follows: $88.7 \%$ of the lower 6 th teeth have 2 roots, $11.3 \%$ of the lower 6 th teeth have 3 roots. $55.6 \%$ of mandibular sixth teeth have 2 separate canals in the mesial root (Vertucci IV). $77.1 \%$ of the mandibular sixth teeth have only one root canal (Vertucci I). The difference in the number of roots as well as the right and left canal morphology was not statistically significant. The difference in number of roots as well as root canal morphology in men and women was not statistically significant.

Key words; root canal, endodontic, cone-beam computed tomographic, mandibular first molar.

\section{I. ĐẶT VẤN ĐỀ}

Để điêu trị nội nha tốt thì điều quan trọng là phải biết về giải phẫu của răng. Việc thiếu kiến thức về các biến thể hình thái và giải phẫu của hệ thống ống tủy có thể dẫn đến việc không xác định được tất cả các ống tủy, không tạo hình và bơm rửa tốt, hậu quả là thất bại trong điều trị

*Trường Đại học Y Dước - Đại học Quốc Gia Hà Nội Chịu trách nhiệm chính: Đinh Diệu Hông

Email: dieuhong201@gmail.com

Ngày nhận bài: 17.3.2021

Ngày phản biên khoa học: 13.5.2021

Ngày duyệt bài: 20.5.2021 nội nha. Các đặc điểm hình thái bên ngoài và bển trong của tủy răng rất phức tạp và mỗi người lại khác nhau.

Những cải tiến trong hê thống hình ảnh kỹ thuật số không xâm lấn, chẳng hạn như phim conebeam $\mathrm{CT}$ và chụp cắt lớp vi tính, cũng như việc sử dụng kính phóng đại trong thực hành lâm sàng, giúp bác sĩ thực hành phát hiện được sự phức tạp của giải phẫu ống tủy.

Các thồng số giải phẫu thường được mô tả trong tài liệu là răng hàm lớn thứ nhất hàm dưới có 2 chân răng và 3 ống tủy mà ít đưa ra các biến thể có thể gặp cũng như tỷ lệ để các bác sĩ lâm sàng cẩn trọng khi điều trị tủy cho bệnh nhân.

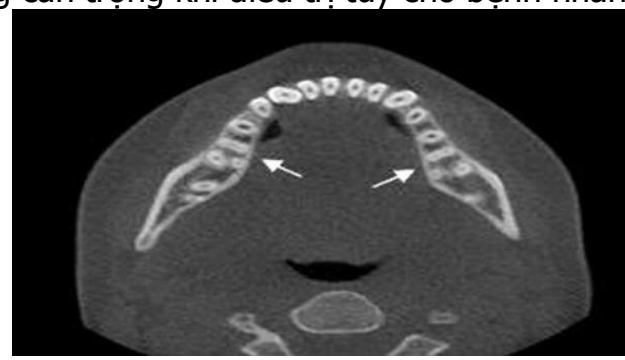

Hình 1: Trường hợp răng số 6 hàm dưới có 3 chân răng với 4 ống tuỷ ở cả bên trái và bên phải

Hiện nay, những tiến bộ công nghệ trong chụp phim răng trên lâm sàng đã cho phép thu được hình ảnh theo 3 chiều không gian, cho phép mô tả chính xác, bao quát và toàn diện về hình thái chân răng và hệ thống ống tuỷ.

Mỗi chủng tộc lại có cấu tạo giải phẫu răng khác nhau, thậm chí đặc điểm vùng miên cũng có thể góp phần tạo sự khác biệt về hình thái và giải phẩu [1],[2]. Do đó, để người thực hành có những dữ liệu tham khảo về hệ thống ống tủy răng số 6 hàm dưới ở người miền bắc chúng tôi đã tiến hành nghiên cứu này với mục tiêu:

3. Xác định số lượng và hinh thái ống tủy của răng số 6 hàm dưới bằng phim Conebeam ở người khu vực Hà Nội và lân cận.

4. Tìm mối liên quan giữa giới tính và hình thái ống tuỷ của răng số 6 hàm dưới.

\section{II. ĐỐI TƯợNG VÀ PHƯƠNG PHÁP NGHIÊN CỨU}

2.1 Đối tượng: Mẫu nghiên cứu gồm 630 răng hàm lớn thứ nhất hàm dưới phải và trái của 315 phim conebeam CT của bệnh nhân Hà Nội và vùng lân cận, gồm 148 nam và 167 nữ, tuổi 
từ 18 đến 55 tuổi.

Tiêu chuẩn chọn mẫu:

1. Có đủ 2 răng số 6 hàm dưới

2.Các răng số 6 hàm dưới có chân răng phát triển hoàn toàn

3.Hình ảnh conebeam CT rõ ràng, thể hiện được hình ảnh các ống tủy.

Tiêu chuẩn loại trữ: Các răng sỗ 6 hàm dưới đã bi

1. Tiêu ngót chân răng

2. Trám bít hoặc có miếng trám đến tủy

3. Phuc hồi kim loai như chốt, mão

4. Nghiêng hoặc mọc ngầm

Cõ̃ mẫu. Răng hàm lớn thứ nhất hàm dưới: dựa vào kết quả nghiên cứu của Huỳnh Hữu Thục Hiền (2019), tỉ lệ răng hàm lớn thứ nhất hàm dưới có $\geq 3$ ống tửy là $16,1 \%$ [3]. Áp dụng vào công tức tính cõ mẫu:

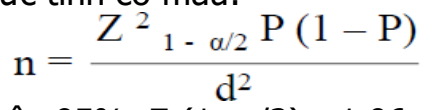

Độ tin cây 95\%, Z (1- a/2) =1,96; d=0,05 Cõ mẫu tối thiểu là 106 răng
2.3. Phương pháp nghiên cứu: Nghiên cứu thực hiện theo thiết kế cắt ngang mô tả phân tích trển conebeam CT. Bệnh nhân được chụp conebeam CT bằng máy Galileos (Sirona Dental System Inc., Đức), kích cõ voxel $0,3 \mathrm{~mm} x$ $0,3 \mathrm{~mm} \times 0,3 \mathrm{~mm}$, Gray scale 12 bit tại bộ môn Răng Hàm Mặt, Trường Đại học Y dược, Đại Học Quốc Gia Hà Nội và phòng chụp Xquang Hà Thành trong khoảng thời gian từ tháng 6 năm 2019 đến tháng 4 năm 2021.

Quan sát hình ảnh bằng phần mềm Galileos Viewer (Sirona Dental System Inc.) trên màn hình 24 inch có độ phân giải $1.920 \times 1.200$, độ tương phản $1.000: 1$, bề dày mỗi lát cắt $1 \mathrm{~mm}$. Trình tự thực hiện như sau:

Đầu tiên, điều chỉnh lát cắt trên cửa sổ Tangential đi qua đúng giữa trục chân răng của từng chân răng số 6 hàm dưới cần đo. Sau đó, điều chỉnh mặt phẳng cắt trên cửa sổ Crosssectional theo đúng trục của răng đước đo. Di chuyển lát cắt trên cửa sổ Axial để kiểm tra số lượng và hình thái ống tủy của mỗi chân răng (hình 2).
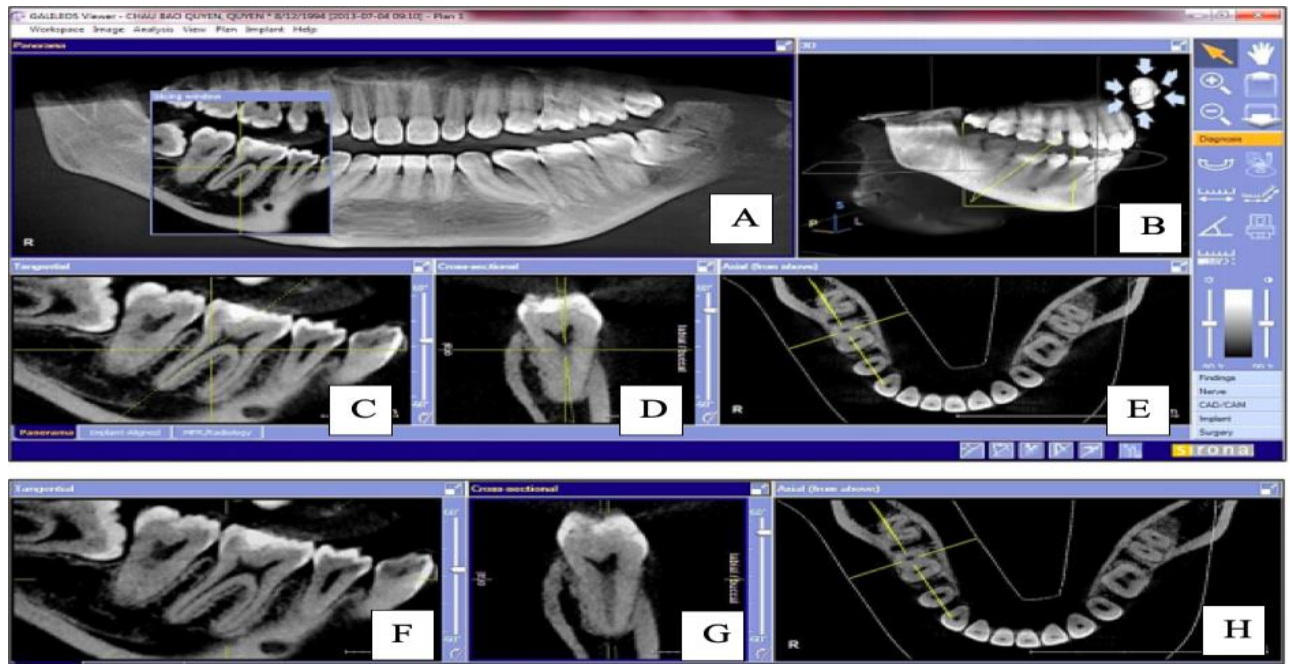

Hình 2: Giao diện phầm mềm Gelileos Viewer, điều chỉnh để quan sát chân ngoài răng hàm lớn thứ nhất hàm dưới bên phải. Chân này có 1 ống tủy, loại I theo Vertucci.

Hình $A, B$ : định vị răng và chân răng cần quan sát

Hình C, D, E: điều chỉnh để quan sát chân xa răng số 6 hàm dưới bên phải

Hình $F, G, H$ : ẩn các đường xác định mặt phẳng trực giao, quan sát trong cả 3 mặt phẳng, di chuyển các lát cắt ghi nhận số lượng ống tuỳ, hình thái ống tuỷ

Điều tra viên chính khảo sát hình ảnh conebeam $\mathrm{CT}$ của từng bệnh nhân để chon bênh nhân và chọn răng thỏa mãn tiêu chuẩn chọn mẫu. Bệnh nhân và răng được chọn được ghi nhận dữ liệu chung và dữ liệu về hình thái chân răng và ống tủy. Quan sát từng răng, từng chân răng, đo ở 2 thời điểm khác nhau, nếu số liệu khác nhau thì sẽ nhờ người thứ 2 kiêm tra.

Hình thái ống tủy: được ghi nhận theo phân loại Vertucci (1984) [4],[5]. Những ống tủy có hình thái khác ngoài phân loại Vertucci được ghi nhận theo số ống tủy thay đổi theo chiều dài chẩn răng từ cổ đến chóp.

Hình thái ống tủy: ghi nhận theo phân loại 
Vertucci (1984) gồm 8 loại (hình 3):

Loại I: chỉ có một ống tủy từ buồng tủy đến lỗ chóp chân răng.

Loại II: có hai ống tủy xuất phát từ buồng tủy tạo thành hai ống tủy riêng biệt nhưng gặp nhau ở gần chóp để thành một ống tủy và ra khỏi chân răng bằng một lỗ chóp.

Loại III: có một ống tủy xuất phát từ buồng tủy nhưng sau đó chia hai và gặp nhau ở gần chóp để tạo một ống tủy và ra khỏi chân răng bằng một lỗ chóp.

Loại IV: có hai ống tủy riêng biệt kéo dài từ buồng tủy tới chóp chân răng.

Loại V: một ống tủy xuất phát từ buồng tủy, sau đó tách ra thành hai ống tủy và đi khỏi chân răng bằng hai lỗ chóp riêng biệt.

Loại VI: hai ống tủy xuất phát từ buồng tủy, kết hợp lại thành một ống tủy và sau đó lại chia hai ở chóp với hai lỗ chóp riêng biệt.

Loại VII: một ống tủy xuất phát từ buồng tủy, chia hai sau đó kết hợp lại thành một ống tủy và lại chia hai ở chóp với hai lỗ chóp riểng biệt.

Loại VIII: có ba ống tủy riêng biệt kéo dài từ buồng tủy đến chóp chân răng.

\section{KẾT QUẢ NGHIÊN CỨU}

3.1. Xác định số lượng và hình thái ống tủy của răng 6 hàm dưới bằng phim Conebeam ở người khu vực Hà Nội và lân cận.

3.1.1. Số lượng chẩn răng 6 hàm dưới Bảng 1: Số lượng chân răng 6 hàm dưới

\begin{tabular}{|c|c|c|c|c|c|c|c|}
\hline \multirow[b]{2}{*}{$\begin{array}{l}\text { Số lượng } \\
\text { chân răng }\end{array}$} & \multicolumn{2}{|c|}{ Răng 36} & \multicolumn{2}{|c|}{ Răng 46} & \multicolumn{2}{|c|}{ Tống } & \multirow[b]{2}{*}{$\mathbf{p}$} \\
\hline & $\begin{array}{c}\text { Số lượng } \\
\text { (n) }\end{array}$ & $\begin{array}{l}\text { Tỷ lệ } \\
(\%)\end{array}$ & $\begin{array}{c}\text { Số lượng } \\
\text { (n) }\end{array}$ & $\begin{array}{l}\text { Tỷ lệ } \\
(\%)\end{array}$ & $\begin{array}{c}\text { Số lượng } \\
\text { (n) }\end{array}$ & $\begin{array}{l}\text { Tỷ lệ } \\
(\%)\end{array}$ & \\
\hline 2 chân & 285 & 90,5 & 274 & 87 & 559 & 88,7 & 0,21 \\
\hline 3 chân & 30 & 9,5 & 41 & 13 & 71 & 11,3 & 0,21 \\
\hline Tống & 315 & & 315 & & 630 & & \\
\hline
\end{tabular}

Số lượng chân răng của răng số 6 hàm dưới 2 bên phải và trái khác biệt nhau không có ý nghĩa thống kề. Răng số 6 hàm dưới có 2 chân răng chiếm $88,7 \%$, răng số 6 hàm dưới có 3 chân răng chiếm 11,3\%. Không gặp trường hợp răng số 6 hàm dưới có 1 chân hoặc nhiêu hơn 3 chân.

3.1.2. Hình thái ổng tủy chân gân của răng 6 hàm dưới hàm dưới theo Vertucci

Bảng 2: Hình thái ống tửy chân gần của răng 6 hàm dưới theo Vertuccí

\begin{tabular}{|c|c|c|c|c|c|c|c|}
\hline \multirow[b]{2}{*}{ Hình thái ống tuỷ } & \multicolumn{2}{|c|}{ Răng 36} & \multicolumn{2}{|c|}{ Răng 46} & \multicolumn{2}{|c|}{ Tống } & \multirow[b]{2}{*}{$\mathbf{P}$} \\
\hline & $\begin{array}{c}\text { Số lượng } \\
\text { (n) }\end{array}$ & $\begin{array}{l}\text { Tỷ lệ } \\
(\%)\end{array}$ & $\begin{array}{c}\text { Số lương } \\
\text { (n) }\end{array}$ & $\begin{array}{l}\text { Tỷ lê } \\
(\%)\end{array}$ & $\begin{array}{c}\text { Số lượng } \\
\text { (n) }\end{array}$ & $\begin{array}{l}\text { Tỷ lệ } \\
(\%)\end{array}$ & \\
\hline Loai I theo Vertucci & 22 & 7,0 & 27 & 8,6 & 49 & 7,8 & 0,55 \\
\hline Loai II theo Vertucci & 96 & 30,5 & 88 & 27,9 & 184 & 29,2 & 0,54 \\
\hline Loai III theo Vertucci & 13 & 4,1 & 19 & 6,0 & 32 & 5,1 & 0,36 \\
\hline Loại IV theo Vertucci & 177 & 56,2 & 173 & 54,9 & 350 & 55,6 & 0,81 \\
\hline Loai V theo Vertucci & 4 & 1,3 & 5 & 1,6 & 9 & 1,4 & 1 \\
\hline Loại VI theo Vertucci & 2 & 0,6 & 2 & 0,6 & 4 & 0,6 & 1 \\
\hline Loại VII theo Vertucci & 1 & 0,3 & 1 & 0,3 & 2 & 0,3 & 1 \\
\hline Loại VIII theo Vertucci & 0 & 0 & 0 & 0 & 0 & 0 & - \\
\hline Tống & 315 & & 315 & & 630 & & \\
\hline
\end{tabular}

Chân gần răng 6 hàm dưới chủ yều có hai ống tủy riêng biệt kéo dài từ buồng tủy tới chóp chân răng (Vertucci IV) chiếm 55,6\%. Sự khác nhau bên phải và trái không có ý nghĩa thống kê. Không 
gặp trường hợp có ba ống tủy riêng biệt kéo dài từ buồng tủy đến chóp chân răng (loại VIII Vertucci). Không quan sát thây ống tuỷ dạng hình chữ $C$ ở chân gần răng số 6 hàm dưới trong nhóm nghiên cứu.

3.1.3. Hình thái ống tủy chân xa của răng 6 hàm dưới hàm dưới theo Vertucci

Bảng 3: Hình thái ống tủy chân xa của răng 6 hàm dưới hàm dưới theo Vertucci

\begin{tabular}{|c|c|c|c|c|c|c|c|}
\hline \multirow[b]{2}{*}{ Hình thái ống tuỷ } & \multicolumn{2}{|c|}{ Răng 36} & \multicolumn{2}{|c|}{ Răng 46} & \multicolumn{2}{|c|}{$\begin{array}{l}\text { Tống } \\
\end{array}$} & \multirow[b]{2}{*}{$\mathbf{P}$} \\
\hline & $\begin{array}{l}\text { Số lượng } \\
\text { (n) }\end{array}$ & $\begin{array}{l}\text { Tỷ lệ } \\
(\%)\end{array}$ & $\begin{array}{c}\text { Số lượng } \\
\text { (n) }\end{array}$ & $\begin{array}{l}\text { Tỷ lệ } \\
(\%)\end{array}$ & $\begin{array}{c}\text { Số lượng } \\
\text { (n) }\end{array}$ & $\begin{array}{l}\text { Tỷ lề } \\
(\%)\end{array}$ & \\
\hline Loai I theo Vertucci & 242 & 76,8 & 244 & 77,5 & 486 & 77,1 & 0,92 \\
\hline Loại II theo Vertucci & 14 & 4,4 & 15 & 4,8 & 29 & 4,6 & 1 \\
\hline Loại III theo Vertucci & 11 & 3,5 & 8 & 2,5 & 19 & 3,0 & 0,64 \\
\hline Loại IV theo Vertucci & 6 & 1,9 & 7 & 2,2 & 13 & 2,1 & 1 \\
\hline Loại V theo Vertucci & 42 & 13,3 & 40 & 12,7 & 82 & 13,0 & 0,91 \\
\hline Loại VI theo Vertucci & 0 & 0 & 1 & 0,3 & 1 & 0,2 & 1 \\
\hline Loại VII theo Vertucci & 0 & 0 & 0 & 0 & 0 & 0 & - \\
\hline Loại VIII theo Vertucci & 0 & 0 & 0 & 0 & 0 & 0 & - \\
\hline Tống & 315 & & 315 & & 630 & & \\
\hline
\end{tabular}

Chân xa răng 6 hàm dưới chủ yếu chỉ có một ống tủy từ buồng tủy đến lố chóp chân răng (Vertucci I) chiếm $77,1 \%$. Sự khác nhau bên phải và trái không có ý nghĩa thống kê. Không gặp trường hợp có một ống tủy xuất phát từ buồng tủy, chia hai sau đó kết hợp lại thành một ống tủy và lại chia hai ở chóp với hai lỗ chóp riêng biệt (loại VII Vertucci) hoặc có ba ống tủy riêng biệt kéo dài từ buồng tủy đến chóp chân răng (loại VIII Vertucci). Không quan sát thây ống tuỷ dạng hình chữ C ở chân xa răng số 6 hàm dưới trong nhóm nghiên cứu.

3.2. Mối liên quan giới tính với hình thái chân răng 6 hàm dưới

3.2.1. Mối liên quan giới tính với số lượng chân răng 6 hàm dưới

Bảng 4: Mối liên quan giữa giới tính với số lượng chân răng số 6 hàm dưới

\begin{tabular}{|c|c|c|c|c|c|}
\hline \multirow{2}{*}{$\begin{array}{c}\text { Số lượng } \\
\text { chân răng }\end{array}$} & \multicolumn{2}{|c|}{ Nam } & \multicolumn{2}{c|}{ Nữ } & \multirow{2}{*}{ P } \\
\cline { 2 - 5 } & Số lượng (n) & Tỷ lệ (\%) & Số lượng (n) & Tỷ lệ (\%) & 0,071 \\
\hline 2 chân & 255 & 86,1 & 304 & 91,0 & 0,071 \\
\hline 3 chân & 41 & 13,9 & 30 & 9,0 & 0,0 \\
\hline Tống & $\mathbf{2 9 6}$ & & $\mathbf{3 3 4}$ & & \\
\hline
\end{tabular}

Số lượng răng 6 hàm dưới có 2 chân ở nam $(86,1 \%)$ ít hơn nữ (91\%), khác biệt không có ý nghĩa thống kê.

3.2.2. Mối liên quan giữa giới tính với hình thái ống tuỷ chân gân răng số 6 hàm dưới

Bảng 5: Mối liên quan giữa giới tính với hinh thái ống tuỷ chân gần răng số 6 hàm dưới

\begin{tabular}{|c|c|c|c|c|c|}
\hline \multirow{2}{*}{ Hình thái chân răng } & \multicolumn{2}{|c|}{ Nam } & \multicolumn{2}{c|}{ Nữ } & \multirow{2}{*}{ P } \\
\cline { 2 - 5 } & Số lượng (n) & Tỷ lệ (\%) & Số lượng (n) & Tỷ lệ (\%) & 0,65 \\
\hline Loại I theo Vertucci & 21 & 7,1 & 28 & 8,4 & 0,65 \\
\hline Loại II theo Vertucci & 82 & 27,7 & 102 & 30,5 & 0,49 \\
\hline Loại III theo Vertucci & 11 & 3,7 & 21 & 6,3 & 0,20 \\
\hline Loại IV theo Vertucci & 176 & 59,5 & 174 & 52,1 & 0,08 \\
\hline Loại V theo Vertucci & 4 & 1,4 & 5 & 1,5 & 1 \\
\hline Loại VI theo Vertucci & 1 & 0,3 & 3 & 0,9 & 0,70 \\
\hline Loại VII theo Vertucci & 1 & 0,3 & 1 & 0,3 & 1 \\
\hline Loại VIII theo Vertucci & 0 & 0 & 0 & 0 & - \\
\hline & 296 & & 334 & & \\
\hline
\end{tabular}
và nữ.

Hình thái ống tuỷ chân gần của răng số 6 hàm dưới theo Vertucci không có sự khác biệt giữa nam

3.2.3. Mối liên quan giữa giới tính với hình thái ống tuỷ chân xa răng số 6 hàm dưới Bảng 6: Mối liên quan giữa giới tính với hình thái ống tuỷ chân xa răng số 6 hàm dưới

\begin{tabular}{|c|c|c|c|c|c|}
\hline \multirow{2}{*}{ Hình thái } & \multicolumn{2}{|c|}{ Nam } & \multicolumn{2}{c|}{ Nũ̃ } & P \\
\cline { 2 - 5 } & Số lượng (n) & Tỷ lệ (\%) & Số lượng (n) & Tỷ lệ (\%) & 0,59 \\
\hline Loại I theo Vertucci & 225 & 76,0 & 261 & 78,1 & 0,48 \\
\hline Loại II theo Vertucci & 16 & 5,4 & 13 & 3,9 & 0,48 \\
\hline Loại III theo Vertucci & 8 & 2,7 & 11 & 3,3 & 0,84 \\
\hline
\end{tabular}




\begin{tabular}{|c|c|c|c|c|c|}
\hline Loại IV theo Vertucci & 6 & 2,0 & 7 & 2,1 & 1 \\
\hline Loại V theo Vertucci & 41 & 13,9 & 41 & 12,3 & 0,64 \\
\hline Loại VI theo Vertucci & 0 & 0,0 & 1 & 0,3 & 1 \\
\hline Loại VII theo Vertucci & 0 & 0,0 & 0 & 0 & - \\
\hline Loại VIII theo Vertucci & 0 & 0,0 & 0 & 0 & - \\
\hline Tống số răng theo giới & 296 & & 334 & & \\
\hline
\end{tabular}

Hình thái ống tuỷ chân xa của răng số 6 hàm dưới theo Vertucci không có sự khác biệt giữa nam và nữ.

\section{BÀN LUẬN}

Trong số 630 răng số 6 hàm dưới được nghiên cứu, chúng tôi nhận thấy chủ yếu là răng có 2 chân răng chiếm $88,7 \%$. Số lượng răng có 2 chân răng bên phải và trái khác biệt nhau không có ý nghĩa thống kê. So với nghiên cứu của Huỳnh Hữu Thục Hiền năm 2019 [3] trên 778 răng số 6 hàm dưới ở người miền nam thì $83,9 \%$ có 2 chân riêng biệt, $16,1 \%$ có 3 chân riêng biệt.

\section{Bảng 7: Số lượng chân răng số 6 hàm dưới trong một số nghiên cứu}

\begin{tabular}{|c|c|c|c|c|c|}
\hline Tác giả & Đối tượng & Cõ̃ mầu & 2 chân & 3 chân & Khác \\
\hline Huỳnh Hữu Thục Hiền, 2019 [3] & CBCT & 807 & $83,9 \%$ & $16,1 \%$ & - \\
\hline Na Ni et al., 2018 [1] & CBCT & 900 & $74,9 \%$ & $25,0 \%$ & $0,1 \%$ \\
\hline Ozkan Miloglu et al., 2012 [2] & CBCT & 533 & $97,6 \%$ & $2,4 \%$ & - \\
\hline Shehadat S.A. et al., 2019 [6] & CBCT & 664 & $95,78 \%$ & $4,22 \%$ & - \\
\hline Sharaan M.E et al., 2017 [7] & CBCT & 218 & $99,5 \%$ & $0,5 \%$ & \\
\hline Đinh Diệu Hồng và cộng sự, 2021 & CBCT & 630 & $88,7 \%$ & $11,3 \%$ & \\
\hline
\end{tabular}

Về hình thái ống tủy chân gần răng số 6 hàm dưới: trong nghiên cứu của chúng tôi, chân gần răng số 6 hàm dưới chủ yếu có 2 ống tuỷ riêng biệt (Vertucci IV) chiếm đến $55,6 \%$, Vertucci II chiếm $29,2 \%$, ngoài ra còn găp Vertucci I, III, V, VI với tỷ lê thấp hơn. Tỷ lệ này có khác biệt với kết quả của các tác giả khác, điều này có thể do đặc điểm giải phẫu của người phía Bắc Việt Nam.

Bảng 8: Hinh thái ống tưy chân gần răng 6 hàm dưới theo Vertucci trong một số nghiên cứu

\begin{tabular}{|c|c|c|c|c|c|c|c|c|c|c|c|}
\hline Tác Giả & $\begin{array}{c}\text { Đối } \\
\text { tượng }\end{array}$ & $\begin{array}{c}\text { Cỡ̃ } \\
\text { mâuu }\end{array}$ & I & II & III & IV & V & VI & VII & VIII & Khác \\
\hline $\begin{array}{c}\text { Huỳnh Hữu Thục } \\
\text { Hiên, 2019 [3] }\end{array}$ & $\mathrm{CBCT}$ & 807 & $8,7 \%$ & $25,0 \%$ & $2,2 \%$ & $56,9 \%$ & $4,3 \%$ & $1,2 \%$ & - & - & $1,6 \%$ \\
\hline Na Ni et al.,2018 [1] & $\mathrm{CBCT}$ & 900 & $3,0 \%$ & $16,6 \%$ & $0,3 \%$ & $76,8 \%$ & $1,3 \%$ & $0,1 \%$ & - & $1,9 \%$ & \\
\hline $\begin{array}{c}\text { Ozkan Miloglu et } \\
\text { al., 2012 [2] }\end{array}$ & $\mathrm{CBCT}$ & 533 & $0,4 \%$ & $32,8 \%$ & $2,3 \%$ & $59,5 \%$ & $2,4 \%$ & $0,4 \%$ & - & $1,3 \%$ & $0,9 \%$ \\
\hline $\begin{array}{c}\text { Sharaan M.E et al., } \\
\text { 2017 [7] }\end{array}$ & $\mathrm{CBCT}$ & 218 & $0 \%$ & $11,93 \%$ & $3,21 \%$ & $83,94 \%$ & $7.78 \%$ & - & $0,92 \%$ & - & \\
\hline $\begin{array}{c}\text { Dinh Diệu Hồng và } \\
\text { cộng sự }\end{array}$ & $\mathrm{CBCT}$ & 630 & $7,8 \%$ & $29,2 \%$ & $5,1 \%$ & $55,6 \%$ & $1,4 \%$ & $0,6 \%$ & $0,3 \%$ & - & - \\
\hline
\end{tabular}

Hình thái ống tuỳ chân xa răng số 6 hàm dưới: trong nghiên cứu của chúng tôi, chủ yếu có 1 ống tuỷ (Vertucci I) chiếm $77,1 \%$, Vertucci $V$ chiếm $13 \%$, các hình thái khác gặp với tỳ lệ thấp hơn. Tỷ lệ này có khác biệt với kết quả của các tác giả khác, điều này có thể do đặc điểm giải phẫu của người phía Bắc Việt Nam.

Bảng 9: Hinh thái ống tủy chân xa răng 6 hàm dưới theo Vertucci trong mốt số nghiên cứu

\begin{tabular}{|c|c|c|c|c|c|c|c|c|c|c|c|}
\hline Tác Giả & $\begin{array}{c}\text { Đối } \\
\text { tượng }\end{array}$ & $\begin{array}{c}\text { Cỡ̂̃u } \\
\text { mâu }\end{array}$ & I & II & III & IV & V & VI & VII & VIII & Khác \\
\hline $\begin{array}{c}\text { Huỳnh Hữu Thục } \\
\text { Hiên, 2019 [3] }\end{array}$ & $\mathrm{CBCT}$ & 807 & $69,1 \%$ & $6,6 \%$ & $5,5 \%$ & $9,3 \%$ & $9,0 \%$ & $0,3 \%$ & - & - & - \\
\hline Na Ni et al.,2018 [1] & $\mathrm{CBCT}$ & 900 & $79,4 \%$ & $6,4 \%$ & $0,7 \%$ & $7,9 \%$ & $5,3 \%$ & - & - & $0,3 \%$ & - \\
\hline $\begin{array}{c}\text { Ozkan Miloglu et } \\
\text { al., 2012 [2] }\end{array}$ & $\mathrm{CBCT}$ & 533 & $74,7 \%$ & $12,3 \%$ & $1,5 \%$ & $9,7 \%$ & $1,8 \%$ & - & - & - & - \\
\hline $\begin{array}{c}\text { Sharaan M.E et al., } \\
\text { 2017 [7] }\end{array}$ & $\mathrm{CBCT}$ & 218 & $62,84 \%$ & $19,72 \%$ & $10,55 \%$ & $2,75 \%$ & $\begin{array}{c}3,67 \\
\%\end{array}$ & - & $\begin{array}{c}0,46 \\
\%\end{array}$ & - & \\
\hline $\begin{array}{c}\text { Einh Diệu Hồng và } \\
\text { cộng sự }\end{array}$ & $\mathrm{CBCT}$ & 630 & $77,1 \%$ & $4,6 \%$ & $3,0 \%$ & $2,1 \%$ & $13 \%$ & $0,2 \%$ & - & - & - \\
\hline
\end{tabular}




\section{KẾT LUẬN}

Số lượng chân răng 2 bên phải và trái khác biệt nhau không có ý nghĩa thống kê. Răng số 6 hàm dưới thường có 2 chân răng $(88,7 \%)$. Sự khác biệt về số lượng chân răng ở hai giới không có ý nghĩa thống kê.

Chân gần răng số 6 hàm dưới chủ yếu có 2 ống tủy riêng biệt kéo dài từ buồng tuỷ tới chóp chân răng (Vertucci IV) chiếm 55,6\%. Sự khác nhau bên phải và trái cũng như sự khác nhau giữa nam và nữ là không có ý nghĩa thống kê.

Chân xa răng số 6 hàm dưới chủ yếu có 1 ống tủy kéo dài từ buồng tuỷ tới chóp chân răng (Vertucci I) chiếm $77,1 \%$. Sự khác nhau bên phải và trái cũng như sự khác nhau giữa nam và nữ là không có ý nghĩa thống kê.

\section{TÀI LIÊU THAM KHẢO}

1. $\mathrm{Na} \mathrm{Ni}$, Shen Cao, Lei Han et al., Cone-beam computed tomography analysis of root canal morphology in mandibular first molars in a Chinese population: a clinical studay. Evidence-Based Endodontics, $2018.23: 1$ (https://doi.org/10.1186/s41121-018-0015-8).

2. Ozkan Miloglu, Hakan Arslan, Cagatay Barutcigil et al., Evaluating root and canal configuration of mandibular first molars with cone beam computed tomography in a Turkish population. Journal of Dental Sciences, 2013. 8, p. 80-86 (http://dx.doi.org/10.1016/j.jds.2012.09.002).

3. Hiên, H.H.T., Đắc Điểm Hình Thái Chân Răng Và Ông Tủy Răng Cối Lớn Thứ Nhất Và Thứ Hai Người Việt Nam. Luận án Tiến sĩ, trường Đại Học Y Dược TP Hồ Chí Minh, 2019.

4. Bansal, R., S. Hegde, and M.S. Astekar, Classification of Root Canal Configurations: A Review and a New Proposal of Nomenclature System for Root Canal Configuration. Journal of Clinical and Diagnostic Research, 2018 (https://doi.org/10.7860/jcdr/2018/35023.11615).

5. Vertucci F.J., Root canal morphology and its relationship to endodontic procedures. Endodontic Topics, 2005. 10, : p. 3-29 (https://doi.org/ 10.1111/j.1601-1546.2005.00129.x).

6. Shehadat S.A., Waheb S., Bayatti S.W.A et al., Cone beam computed tomography analysis of Root and Root canal Morphology of First permanent lower molars in a Middle East Subpopulation. Journal of International Society of Preventive \& Community Dentistry, 2019. 9(5). p: 458-463.

7. Sharaan M.E., Elrawdy A.M., An evaluation of mandibular molars root canal morphology using cone-beam computed tomography in an Egyptian subpopulation. Tanta Denatal Journal, 2017. 14, p: 220-224 (https://doi.org/10.4103/tdj.tdj_50_17).

\section{ĐĂC ĐIỂM TỔN THƯƠ'NG VÕNG MẠC TRÊN BỆNH NHÂN ĐÁI THÁO ĐƯỜNG LỌC MÁU CHU KÌ}

Vũ Tuấn Anh*

\section{TÓM TẮT}

Mục tiêu: Mô tả đăc điểm lâm sàng của tổn thương võng mạc trên bệnh nhân bị bệnh đái tháo đường (ĐTĐ) đang lọc máu chu kì. Đối tượng và phương pháp nghiền cứu: nghiên cưú mô tả trên 63 bệnh nhân ĐTÐ đang lọc máu chu kỳ (126 mắt), thu thập các thông tin cơ bản (tuổi, giới, thời gian mắc ĐTÐ, typ ĐTÐ, thời gian lọc máu ...), khám đáy mắt và chụp ảnh võng mạc kỹ thuật số tiêu chuẩn xác định tổn thương của bệnh võng mạc ĐTĐ và tổn thương phối hợp . Kết quả: tuổi bệnh nhân trung bình 54士 9,7 (23-77); nam giới chiếm $65,1 \%$; đa số số mắt đều có thị lực giảm 89,5\% (113/126); hâuu hết mắc bệnh võng mạc ĐTĐ (125/126 mắt), trong đó giai đoạn chưa tăng sinh nhe và vừa là $65,9 \% \%$ (83 mắt), tiền tăng sinh $20,6 \%$ (26 mắt) và tăng sinh $12,7 \%$ (16 mắt), tỷ lệ phù hoàng điểm 19,8\% (25 măt). Kết luận: tổn thương võng mạc của bệnh

*Bệnh viện Mắt trung ương.

Chịu trách nhiệm chính: Vũ Tuấn Anh

Email: vta.oph@gmail.com

Ngày nhận bài: 16.3.2021

Ngày phản biên khoa học: 14.5.2021

Ngày duyệt bài: 21.5.2021 nhân ĐTĐ có lọc máu chu kì là rất nặng và có nhiều tổn thương phối hợp, vì vậy việc khám võng mạc có chụp ảnh võng mạc không thuốc cản quang sớm và định kỳ có thể giúp phát hiện và can thiệp sớm các biến chứng năng ở mắt.

Tư khóa: bệnh võng mạc đái tháo đường, lọc máu chu kỳ

\section{SUMMARY}

RETINAL LESION FEATURES OF HEMODIALYSIS

PATIENTS WITH DIABETES MELLITUS

Purpose: Descibe the retinal lesion features in patients with diabetes mellitus on hemodialysis. Materials and Methods: observational study, 126 eyes of 63 diabetes patients on hemodialysis, grading for retinal lesion $(R 0 \rightarrow R 4)$, macular lesion (M0, M1) following the criteria of the ICO classification and find out other retinal lesions. Results: demography: age average $54 \pm 9.7(23-77), 65.1 \%$ were male, majority of eyes has vision impairment $89,5 \%(113 / 126)$; almost had DR (125/126) included R1-R2 65.9\%, R3 20.6\%, R4 $12.7 \%$ and macular edema (M1) prevalence was $19.8 \%$. Conclusion: prevalence of DR in DM on hemodialysis group was remarkable, so the DR screening by eye check and digital fundus camera scan for this special group would be necessary. 